\author{
Елена Хабибуллина, Елена Маклеева \\ Казанский федеральный университет (Казань, Россия)
}

\title{
РАБОТА С ПРОИЗВЕДЕНИЯМИ Ю. КОВАЛЯ НА ЗАНЯТИЯХ ПО ФИЛОЛОГИЧЕСКОМУ АНАЛИЗУ ТЕКСТА С ИНОСТРАННЫМИ СТУДЕНТАМИ
}

В методике преподавания русского языка как иностранного (РКИ) работе с художественным текстом традиционно придается важное значение. Безусловно, подходы к ней меняются в зависимости от дисциплины, в рамках которой оказывается задействованным такой текст.

Первое представление об анализе текста иностранцы, изучающие русский язык, получают на занятиях по чтению. Однако, использование художественных текстов на уроках чтения может сводиться к минимуму, если целью преподавателя является подготовка к сдаче соответствующего субтеста в рамках тестирования (ТРКИ). В большинстве случаев основное внимание обращается на ознакомительное и просмотровое чтение, в то время как чтение изучающее остается на периферии. Занятия же по филологическому анализу текста ориентированы на то, что именно изучающее чтение будет задействовано при работе с текстом. У иностранных студентов-филологов, приезжающих на годичную стажировку в российские университеты, изучение таких дисциплин, как «Лингвистический анализ художественного текста», «Филологический анализ текста» вызывает определенные затруднения: несмотря на то, что они достаточно хорошо овладевают теоретическим материалом, терминологическим аппаратом дисциплин, интерпретация неадаптированного текста дается им нелегко. Перед преподавателями, работающими с магистрантами, встают еще более сложные задачи, поскольку в магистратуру по специальности «Филология. Русский язык как иностранный» не всегда поступают те, кто окончил бакалавриат по филологии или лингвистике, приходится учитывать, что у обучающихся может быть недостаточная степень владения лингвистической терминологией, не так хорошо сформирован навык выявления языковых единиц, значимых для понимания идеи текста.

Еще одна проблема, с которой сталкивается преподаватель, - выбор текстов для анализа. В работах, посвященных методике чтения на уроках РКИ, 
обращается особое внимание на отбор текстов в соответствии с определенными критериями. В частности, отмечается, что текст или текстовый фрагмент должен мотивировать обучаемых к чтению, быть информативным для них и отвечать их эстетическим потребностям. Бытует мнение, что преподаватель может предлагать обучаемым выбор текста для чтения, в этом случае они будут более мотивированы и уроки чтения будут более продуктивными, причем рекомендуется активнее обращаться к произведениям современных авторов. Однако далеко не всегда такой вариант работы возможен и вопрос о том, что из современной литературы интересно было бы читать на занятиях, может остаться без ответа, поскольку в представлениях студентов о российской литературе нередко бытуют только хрестоматийные имена писателей-классиков - А. С. Пушкин, Л. Н. Толстой, А. П. Чехов.

Безусловно, классические произведения - обязательный элемент занятий по филологическому и лингвистическому анализу текста в иностранной аудитории, тем более что существуют хорошие методические разработки в помощь преподавателю (напр., Вартаньянц 1986). Произведения литературы конца XX века также нередко становятся объектом внимания методистов, однако перечень авторов достаточно предсказуем: Л. Улицкая, Л. Петрушевская, Т. Толстая (Кулибина 2001). Имена других российских писателей $\mathrm{XX}$ века, героями произведений которых являются не только горожане, но и деревенские жители, студентам и магистрантам неизвестны, а между тем в их текстах заложен большой гуманистический и культурный потенциал. К числу таких авторов, безусловно, относится Ю. И. Коваль. В данной работе мы предлагаем вариант работы с текстами его рассказов о природе. Отбор рассказов («Снеги белы» и «Солнце и снег») осуществлялся, в первую очередь, по языковому критерию - текст не должен быть излишне трудным для понимания в лексическом и грамматическом плане (аудитория при этом владеет русским языком приблизительно в объеме второго сертификационного уровня), кроме того, здесь должны быть средства выразительности, которые студенты или магистранты в состоянии сами найти в ходе домашнего чтения текста перед аудиторным занятием. Основные задачи урока - показать, на что в первую очередь следует обращать внимание при изучении произведений, в которых значимыми являются образы природы, сформировать навык анализа пространственно-временного континуума, развить навык анализа роли лексических единиц в тексте.

Приступая к работе с художественными произведениями о природе, прежде всего мы напоминаем студентам о том, что важной составляющей здесь является категория времени, при этом текстовое время нередко представлено как циклическое, поскольку описание природы невозможно без указания на сезон природного цикла. В частности, характерной чертой темпорального пространства в рассказах Ю. Коваля о природе является повторяемость - времена года постоянно сменяют друг друга, кроме того, автор обращает 
внимание на пограничные моменты - переход одного сезона в другой, как, например, в рассказе «Снеги белы». Поскольку рассказ небольшой, приведем его здесь полностью:

\section{Снеги бель}

Холодные уже наступили времена. Тёмные настали долгие ночи. Вечерами всё сидит Орехьевна у окна, вяжет варежки и напевает:

У меня пред окном

Распустилась сирень...

- Сирени теперь долго не дождаться, - сказал я. - Про сирень - не время петь. Зима на носу. Грачи последние улетают.

- Про сирень всегда время петь. И зимой, и летом.

Она отложила вязанье, глянула в потолок и вдруг запела:

- Снеги бель выпадали.

- Охотнички выезжсали! - подхватил я.

Так мы пели и глядели в потолок - наверно, потому, что откуда-то оттуда, из высот запотолочных, ожидали мы снега.

А наутро, когда я проснулся, Орехьевна сказала:

- Накликали мы с тобой, зазвали, наманили...

Необыкновенно светло было в избе. Серебряный, снежный свет шёл из окон.

Я надел валенки, выскочил на улииу.

Первый снег этого года ровно и плотно лёг на землю. Всё покрыл: и крыши, и дорогу, и дальние лесные поляны.

Сосед наш, Ляксандрыч, вышел на улииу, и тоже в валенках.

- Вот теперь и считай, - сказал Ляксандрыч. - Через сорок дней ляжет настоящий снег, а это - первая порома. Она скоро растает.

Для того чтобы подготовить студентов к работе на уроке, преподаватель предлагает им дома ответить на следующие вопросы:

1. Где происходит действие рассказа?

2. В какое время года происходит действие рассказа? Докажите это примерами из текста.

3. Найдите в тексте слова и словосочетания, которые обозначают время года, время суток.

4. Что вы можете сказать о персонажах?

Во время аудиторной работы учащиеся, отвечая на первый вопрос, отмечают, что действие происходит в деревне, об этом свидетельствуют следующая деталь: герои живут в избе. На это же указывают имена персонажей. В рассказе кроме автора-повествователя присутствуют герои, названные Орехьевна и Ляксандрыч. Обучающиеся, владеющие русским языком на продвинутом уровне, обычно понимают, что Орехьевна и Ляксандрыч - обращения по отчеству. Преподаватель поясняет, что в этих наименованиях отражены особенности диалектного произношения, характерного для деревенских жителей (правильно отчества героев будут написаны как Арефьевна и Алек- 
сандрович). Такой прием помогает автору объективизировать пространство. Повествователь носителем диалекта при этом не является (поскольку в тексте в его речи подобных примеров больше нет), используя деревенский вариант наименования персонажей, он подчеркивает свою симпатию к ним.

Преподаватель напоминает, что изображаемое в художественном тексте пространство может быть разным. Обычно противопоставляются пространство закрытое и открытое, в данном тексте закрытое пространство представлено лексемой изба, открытое создается словами и словосочетаниями, задающими горизонтальный (улица, дорога, дальние лесные поляны) и вертикальный (крыши) векторы. При этом пространственные границы как бы стираются: во время пения герои поднимают глаза к потолку, но мысленно представляют себе небо, в тексте оно обозначено окказиональной перифразой (запотолочные высоты). Таким образом автор дает понять, что в деревне человек лучше понимает и чувствует природу, поскольку оказывается близок к ней, больше зависит от нее.

В ходе ответа на второй вопрос учащиеся выделяют словосочетания, которые описывают позднюю осень: холодные времена, темные долгие ночи, первый снег, зима на носу. Кроме того, можно отметить такой темпоральный указатель, как грачи последние улетают и напомнить студентам известный весенний пейзаж А. К. Саврасова «Грачи прилетели», чтобы подчеркнуть, что отлет и появление этих птиц прочно связан в народном сознании со сменой сезонов.

Как обозначение времени суток учащиеся выделяют слова ночи, вечерами, наутро, а как обозначение времен года - зима, зимой, летом. Преподаватель обращает внимание на то, что в тексте присутствуют лексемы, которые также выполняют роль хронологических помет: сирень (кустарник, который цветет весной), пороша, сирени теперь долго не дождаться. Такого рода работа с лексическим материалом помогает сформировать навыки анализа временного континуума. При этом задача преподавателя - привести учащихся к выводу о том, что в картине мира автора нашло отражение народное восприятие природного цикла, когда каждое время года имеет свои приметы и описывается в устойчивых словесных образах.

Продолжая анализ средств репрезентации временного континуума, преподаватель предлагает студентам подчеркнуть наречия с временной семантикой, среди них найти пары слов, противоположных по значению. Это слова время - не время, теперь - всегда в споре о песне между повествователем и Орехьевной. Весенняя, быстро отцветающая сирень выступает как символ вечной красоты, воспоминания о которой согревают душу и для которой всегда время.

Центральный эпизод рассказа - появление первого снега, предвещающего наступление зимы. Преподаватель просит найти однокорневой повтор в описании первого снега - cвет, светло - и объяснить его использование. 
Студенты отмечают, что это средство экспресии, таким образом автор хочет подчеркнуть красоту происходящего. Этой же цели служат эпитеты в словосочетаниях серебряный, снежный свет, необыкновенно светло. Цветовой контраст, выраженный словами темный (ночью) - светло (утром), подчеркивает неожиданность происходящего для повествователя (первый снег этого года), в то время как для деревенского жителя Ляксандрыча это событие ожидаемое, повторяющееся, не случайно с ним связана народная примета - через сорок дней ляжет настоящиий снег.

Бытовые детали в рассказе также несут определенную смысловую нагрузку как репрезентанты циклического времени, так, в тексте есть упоминание типичных элементов русской национальной зимней одежды - варежки и валенки: в ожидании зимы вяжет варежки Орехьевна, повествователь выбегает посмотреть на первый снег в валенках, в валенках же выходит на улицу Ляксандрыч.

Анализируя категорию времени в тексте, нельзя обойти вниманием видо-временные формы глаголов, это поможет также актуализировать знание о языковых средствах оформления функционально-смысловых типов текста в русском языке. Для повествования характерно использование глаголов в форме прошедшего времени, и в рассказе Ю. Коваля в повествовательных фрагментах преимущественно появляются глаголы совершенного вида в форме прошедшего времени, в описательных фрагментах - находим глаголы настоящего времени несовершенного вида. В рассуждении, представленном в прямой речи персонажей, используются формы настоящего времени. Но поскольку образ циклического времени - основной в рассказе, в финальной реплике Ляксандрыча появляется проспекция - глаголы использованы в форме будущего времени, с помощью этого приема еще раз акцентируется, что события, очевидцем которых является повествователь, - один из этапов природного цикла.

Рассказы Ю. Коваля о природе представляют ценный материал для отработки навыка анализа средств художественной выразительности, в том числе их способности не просто украшать речь, но и способствовать выражению идейного содержания произведения. Проиллюстрируем это на примере использования олицетворения в рассказе «Солнце и снег».

\section{Солнце и снег}

С утра багряное, днём лимонное, стало к вечеру зимнее солнце извета ягоды морошки. Но тепла морошка-ягода, а зимнее солнце - прохладно. Чуть скользят его лучи по деревьям и крышам домов, скользят-пролетают по снежным сугробам.

Ослабело зимнее солние, никак не может согреть снег, растопить, привести поскорей весну. Быстро склоняется солние за лес, уходит с небесного склона.

Солние и снег вроде бы не такие уж большие друзья. Всю зиму старается солние растопить снег, да ничего не выходит. 
Как-то вечером шёл я по лесной дороге, смотрел, как сверкает снег под последними солнечными лучами, и вдруг понял, что солнце вовсе и не старается растопить снег. Оно ласкает снег утром багряными, днём лимонными, а вечером лучами ияета ягоды морошки.

Ласкает его, балует. Ладно уж, полежи, брат, полежи в лесах до весны.

В этом рассказе благодаря использованию тропов создается удивительная картина зимней природы. Главным из них является олицетворение. С его помощью неживая природа изображается как одушевленная, в результате текст приобретает эмоциональность и экспрессию. Фактически олицетворение выполняет текстообразующую роль в этом рассказе, поскольку проходит через весь рассказ и способствует выражению идеи автора.

В начале работы учащимся предлагается ответить на следующие вопросы:

1. Выделите основные образы в тексте.

2. Подчеркните слова, которые являются наиболее важными в создании образов природы.

Учащиеся без труда определяют, что в рассказе три основных образа: солнце, снег и образ повествователя. Работая с лексикой, которая используется автором для воплощения образов природы, они сравнивают объем языкового материала и делают вывод о том, что солнце находится в центре внимания повествователя, прием олицетворения реализуется здесь через глаголы - старается, ласкает, балует. Снег предстает как объект воздействия солнца, поэтому олицетворение реализуется уже не через глаголы, а через описание «взаимоотношений» солнца и снега, причем первоначальное предположение повествователя о «вражде» солнца и снега в конце рассказа опровергается.

Далее преподаватель задает вопрос: «В какой известной русской народной сказке говорится том, что солнце опасно для снега?» Обычно сразу называют сказку «Снегурочка». В итоге студенты делают вывод о том, что повествователь сначала опирается на традиционное противопоставление снега и солнца. Преподаватель просит найти в тексте объяснение, почему солнце не может растопить снег. После того как студенты нашли слова зимнее солнце - прохладно, ослабело зимнее солнще, преподаватель предлагает им сравнить мнение повествователя с народными представлениями о зимнем солнце и может привести в качестве иллюстрации пословицу Зимой солнце светит, да не греет.

Общий вывод на данном этапе работы - сначала в рассуждениях автора находят отражение устойчивые народные представления, в которых жизнь природы отражена в оппозициях (например, тепло-холод), но затем его мнение меняется.

Чтобы учащиеся могли ответить на итоговый вопрос: «Чем объясняется изменение позиции автора?», необходимо проанализировать финальную 
фразу рассказа: Ладно уж, полежи, брат, полежи в лесах до весны. Преподаватель поясняет, что это - несобственно-прямая речь, и просит определить, кому принадлежит эта фраза и кому она адресована. После того как студенты определят, что адресатом является снег и что автор представляет, как солнце обращается к нему с этими словами, им предлагается подумать над тем, почему именно форма несобственно-прямой речи выбрана в данном случае.

В ходе лекционных занятий студенты получают общее представление о функциях чужой речи в тексте, в частности, о том, что несобственно-прямая речь свидетельствует о сближении внутреннего мира персонажа и автора (рассказчика). При прочтении рассказа они констатируют, что повествователь - человек, любящий природу. Именно поэтому он в итоге понимает, что в природе даже такие противоположные явления, как снег и солнце, не противопоставлены друг другу, а представляют собой гармоничное разнообразие мира (об этом свидетельствует, прежде всего, обращение брат) и поэтому заканчивает свой рассказ фразой как будто принадлежащей солнцу, но на самом деле отражающей его собственные представления о мире.

Прежде чем сделать выводы по итогам анализа, преподаватель просит студентов подумать о том, какие качества помогли рассказчику забыть о стереотипах и прийти к открытию. Учащиеся отмечают такие черты рассказчика, как внимательность, умение видеть красоту.

В конце урока делаются выводы об идейном содержании и своеобразии произведений:

- в проанализированных рассказах Ю. Коваля повествование ведется от первого лица, фактически в рассуждениях повествователя выражаются чувства и мысли автора;

- в центре внимания оказываются типичные явления природы, но задача автора показать их особенность, таким образом основная идея проанализированных текстов - надо учиться видеть прекрасное и необычное в обыденном;

- опираясь на существующие в народной культуре представления о жизни и устройстве окружающего мира (циклическое видение времени), автор проявляет индивидуальность в оценке и интерпретации явлений природы.

Предложенный нами вариант работы с текстами Ю. Коваля на занятиях по филологическому анализу текста прошел апробацию в группах студентов-филологов и магистрантов из Китая. Сравнительно небольшое количество языковых трудностей, четкая структура позволяют студентам неплохо понимать их содержание. Апелляция к общечеловеческим ценностям и при этом ориентированность на русскую народную культуру делают эти рассказы интересными в познавательном плане. Несмотря на небольшой объем, тексты дают хороший материал для иллюстрации ряда понятий, изученных в рамках теоретической части курсов филологического анализа. 


\section{Библиография}

Болотнова Н. С. (2009), Филологический анализ текста: учеб. пособие, Москва.

Вартаньянц А. Д., Якубовская М. Д. (1986), Пособие по анализу художественного текста для иностранных студентов-филологов, Москва.

Кулибина Н. В. (2001), Зачем, что и как читать на уроке. Художественный текст при изучении русского языка как иностранного, Санкт-Петербург.

Кулибина Н. В. (2000), Художественный текст в лингводидактическом осмыслении, Москва.

Купина Н. А., Николина Н. А. (2011), Филологический анализ художественного текста. Практикум [Электронный ресурс], Режим доступа: http://znanium.com/bookread.php? book=406111.

Проблемы преподавания филологических дисциплин иностранным учащимся: Материаль 3-й Международной научно-методической конферениии (2014), Воронеж.

Рогова К. А. и др. (2011), Текст: теоретические основания и принципы анализа: учебно-научное пособие, Москва.

Хабибуллина Е. В. (2013), Сакральные образы в рассказе И. С. Тургенева «Живые мощиџ: лингвокультурный аспект, «Филология и культура», № 3 (33), с. 153-156.

Щукин А. Н. (2012), Теория обучения иностранным языкам (Лингводидактические основы). Учебное пособие для преподавателей и студентов языковых вузов, Москва.

Коваль Ю. И. Снеги бель, Режим доступа: http://www.planetaskazok.ru/kovalras, дата обращения: 19.03.2017.

Коваль Ю. И Солниее и снег, Режим доступа: http://www.planetaskazok.ru/kovalras, дата обращения: 19.03.2017.

Fattakhova N. (2014), Tsze Gen, Fedorova N., The functioning of lexical items rain and snow in Russian and Chinese folk omens //Conference proceedings (SGEM conference on anthropology, archaeology, history, philosophy) (1-10 september, 2014), Albena. Bulgaria, c. 193-201.

\section{Elena Chabibullina, Elena Makleeva}

\section{WORK WITH THE LITERARY TEXTS OF YU. KOVAL AT THE LESSONS OF THE PHILOLOGICAL ANALYSIS OF THE TEXT WITH FOREIGN STUDENTS}

(Summary)

Work with literary text is very important in the process of teaching Russian as a foreign language. At the lessons of reading we pay more attention on the text content, but when we work with students-phylologists we should teach them how to analyse the text, how to find the connection of form and content, how to find linguistic means, which help to understand the idea of the text. In this article we offer methodical research that can help the teachers, who conduct the practical lessons of the text analysis. In the course of the work the following methods were used: the method of observation, the method of contextual analysis, the method of pragmatic text analysis, the comparative-contrastive method. We proposed a variant of constructing a lesson of philological analysis of the text using as an example two stories written by Yu. Koval. The choice of this textual material is motivated by the fact that according to linguistic and extralinguistic characteristics it is suitable for use in a foreign language audience, working with it allows us to achieve the main 
objectives of the lesson of the philological analysis of the text with foreigners: to teach students the identification and interpretation of linguistic phenomena to determine the author's intentions, generate respect and interest in Russian literature, to transform the skills of reading for detail into the skills of text analysis.

Keywords: philological analysis, Russian as a foreign language.

\section{РАБОТА С ПРОИЗВЕДЕНИЯМИ Ю. КОВАЛЯ НА ЗАНЯТИЯХ ПО ФИЛОЛОГИЧЕСКОМУ АНАЛИЗУ ТЕКСТА С ИНОСТРАННЫМИ СТУДЕНТАМИ}

(Резюме)

Работа с художественным текстом на занятиях РКИ занимает важное место в процессе обучения русскому языку как иностранному. Если на занятиях по чтению основное внимание уделяется пониманию содержания текста, то работа с художественным текстом у студентов филологических специальностей предполагает, что они учатся анализировать, как форма выражения связана с содержанием, выявлять те языковые средства, которые помогают понять его идею. В данной статье предлагается методическая разработка в помощь преподавателю, ведущему практические занятия по анализу текста. В ходе работы использованы следующие методы: метод наблюдения, метод контекстуального анализа, метод прагматического анализа текста, сравнительно-сопоставительный метод. Нами предложен вариант построения занятия по филологическому анализу текста на примере двух рассказов Ю. Коваля. Выбор данного текстового материала обосновывается тем, что по лингвистическим и экстралингвистическим характеристикам он подходит для применения в иноязычной аудитории, работа с ним позволяет достичь основных целей занятия по филологическому анализу текста с иностранцами: научить студентов выявлению и интерпретации языковых явлений для определения авторских интенций, сформировать уважение и интерес к русской литературе, трансформировать умения и навыки изучающего чтения текста в навыки его анализа.

Ключевые слова: филологический анализ, русский язык как иностранный. 